\title{
Saberes do aluno e intervenção docente: uma prática de produção textual
}

\author{
Knowledge of student and teacher intervention: a textual production practice
}

\section{Conocimientos del estudiante e intervención docente: una práctica de producción textual}

\author{
ELIANETG DiAS KANTHACK* \\ GISLENE APARECIDA DA SILVA BARBOSA** \\ RENATA JUNQUEIRA DE SOUZA***
}

\begin{abstract}
RESUMO
O artigo apresenta o processo e os resultados de uma avaliação diagnóstica de escrita aplicada em alunos de $6^{\circ}$ ano e também propõe uma sequência didática como intervenção docente. Com base na escrita de um conto, é avaliada a capacidade do estudante de identificar e de materializar os elementos da língua, garantindo a construção de sentido: uso do discurso direto, paragrafação, uso de coesivos, registro das letras maiúsculas e minúsculas, registro das ações, presença dos elementos da narrativa. A análise dos resultados e a proposta das práticas educativas sustentam-se nas pesquisas de Dolz e Schnewly (2004) sobre estratégias metodológicas para ensinar a produção de texto na escola, com base em um gênero textual, de relevância nas práticas cotidianas, destacando o procedimento de sondagem da aprendizagem como eixo e ponto de referência para o planejamento e para a realização de significativas intervenções docentes.
\end{abstract}

Palavras-chave: Aprendizagem da escrita. Avaliação diagnóstica. Metodologia do ensino.

\begin{abstract}
The article presents the process and the result of a diagnostic evaluation of writing applied for students of elementary school (6th grade - in Brazilian school) and proposes a Didactic Sequence for teacher intervention. Based on a short story, it evaluates the student's ability to identify and recognize the language elements, ensuring the construction of meaning: the use of direct speech, paragraphing, use of cohesive, record of uppercase and lowercase letters, registration of actions and the presence of narrative elements. The analysis and the proposal of educational practices are b ased on the research of Dolz and Schnewly (2004) on methodological strategies for teaching writing at school, based on a genre of relevance in daily practices, highlighting the procedure of learning as axis and reference point for the planning and realization of significant teaching interventions and practices.
\end{abstract}

Keywords: Writing learning. Diagnostic evaluation. Methodology of teaching.

\section{RESUMEN}

El artículo presenta el proceso y los resultados de una evaluación de escritura aplicada en los estudiantes de $6^{0}$ año y también propone una Secuencia Didáctica como una intervención del maestro. Basado en la escritura de un cuento, se evalúa la capacidad del estudiante para determinar y realizar los elementos del lenguaje, lo que garantiza la construcción del sentido: el uso de la palabra directa, en párrafos, uso de cohesión, registro de letras mayúsculas y minúsculas, el registro de acciones, presencia de elementos de la narrativa. El análisis y la propuesta de las prácticas educativas se basan en la investigación de Dolz y Schnewly (2004) sobre las estrategias metodológicas para la producción de textos en la escuela, a partir de un género textual de relevancia en las prácticas diarias, destacando el procedimiento de descubierta de los conocimientos del alumno como eje y punto de referencia para la planificación y la realización de intervenciones de enseñanza.

Palabras clave: Aprendizaje de la escritura. La evaluación diagnóstica. Metodología de la enseñanza.

* Mestrado e Doutorado na área de Educação pelo PPGE da UNESP, Marília-SP. Professora Assistente Doutor na FFC da Universidade Estadual Paulista Júlio de Mesquita Filho, Marília-SP. Pesquisadora da área da Educação, com ênfase em Política Educacional, Formação de Professores e Ensino da Leitura e da Escrita.E-mail: <netezeu@gmail.com>.

** Possui graduação em Letras, especialização em Gestão Educacional, mestrado e doutorado em Educação, todas as formações pela Universidade Estadual Paulista Júlio de Mesquita Filho (UNESP).E-mail: <barbosagislene@gmail.com>.

*** Possui graduação em Letras pela Universidade Estadual Paulista Júlio de Mesquita Filho, mestrado em Linguística e Letras pela Pontifícia Universidade Católica do Rio Grande do Sul (PUCRS), doutorado em Letras pela Universidade Estadual Paulista Júlio de Mesquita Filho (UNESP).E-mail: <recellij@ gmail.com>. 


\section{INTRODUÇÃO}

Considerando a importância da língua escrita na sociedade contemporânea e reconhecendo que a escola é o local, por excelência, para o desenvolvimento intencional das práticas de linguagem, torna-se relevante considerar que "a complexidade da atividade escrita justifica o caráter longo e árduo de sua aprendizagem" (DOLZ, GAGNON E DECÂNDIO, 2010, p. 31). Assim, investigações sobre as práticas de produção de texto na escola se tornam essenciais para descobrir o que sabem os estudantes e de quais maneiras os professores podem agir na realização da tarefa de ensinar.

Além disso, o exercício pleno da cidadania, segundo o conceito de Letramento, está vinculado ao desenvolvimento da capacidade de ler e de escrever com sucesso os mais diferentes gêneros discursivos que medeiam as relações humanas (SOARES, 2002). Portanto, a preocupação com a qualidade da compreensão e escrita de textos dos alunos é necessária para que a escola cumpra sua função social.

O objetivo deste artigo é compartilhar os resultados de uma sondagem de produção de texto aplicada em uma turma de $6^{\circ}$ ano, de uma escola pública estadual na cidade de Presidente Prudente (SP), e também compartilhar uma proposta de intervenção docente pelo uso de uma sequência didática. A atividade diagnóstica foi aplicada em fevereiro de 2015, mês em que se iniciou o ano letivo, e foi desenvolvida com 26 alunos (com idade entre 10 e 13 anos, os quais serão identificados pelas iniciais de seus nomes). Trata-se de uma sondagem dos conhecimentos prévios dos estudantes de 6 a ano que acabaram de chegar à escola dos anos finais do Ensino Fundamental, uma análise solicitada pela Secretaria Estadual de Educação de São Paulo (SEE-SP) - "Avaliação da Aprendizagem em Processo". A mediação foi desenvolvida pela professora de Língua Portuguesa da turma e a análise dos dados foi realizada durante o mês de março. Já a proposta de intervenção com o uso de uma sequência didática foi desencadeada a partir disso.

A seguir, apresentam-se as intervenções iniciais feitas pela docente antes, durante e após a aplicação da avaliação, os resultados dos saberes dos alunos quanto à língua escrita e a proposta de desenvolvimento de uma sequência didática.

\section{A PROduÇão TeXtúl no PROCESSO REFLEXIVO}

O caminho indicado por pesquisadores para o desenvolvimento de leitores e escritores competentes na escola básica baseia-se na sistematização das atividades de leitura e escrita. Soares (2003) afirma que esse processo de sistematização ou escolarização é necessário para organizar o trabalho educativo e inevitável na escola, cuja essência sustenta-se em procedimentos formalizados e organizados em categorias.

não há como ter escola sem ter escolarização de conhecimentos, saberes, artes: o surgimento da escola está indissociavelmente ligado à constituição de "saberes escolares", que se corporificam e se formalizam em currículos, matérias e disciplinas, programas, metodologias, tudo isso exigido pela invenção, responsável pela criação da escola, de um espaço de ensino e de um tempo de aprendizagem (SOARES, 2003. p. 20).

Visto que a aula de Língua Portuguesa tem como tarefa central o desenvolvimento de alunos leitores e escritores, torna-se importante encontrar possibilidades de realizar a transposição didática sem desprezar o dinamismo da linguagem e a reflexão sobre os usos sociais da língua e dos textos.

o transposição didática é inevitável, mas deve ser rigorosamente controlada. É inevitável porque o propósito da escola é comunicar o saber, porque a intenção de ensino faz com que o objeto não possa aparecer exatamente da mesma forma, nem ser utilizado da mesma maneira que é utilizado quando essa intenção não existe [...]. Como o objetivo final do ensino é que o aluno possa fazer funcionar o aprendido fora da escola, em situações que já não serão didáticas, será necessário manter uma vigilância epistemológica que garanta uma semelhança fundamental entre o que se ensina e o objeto ou prática social que se pretende que os alunos aprendam (LERNER, 2002, p. 35).

Diante disso, a aplicação da Avaliação da Aprendizagem em Processo requer a mediação docente para que o aluno saiba o que deve fazer e possa mostrar o que sabe no momento em que escreve. Portanto, é importante dividir as ações em antes, durante e depois da escrita do aluno. A seguir, está relatada, brevemente, cada etapa:

Antes da escrita. $O$ primeiro passo dessa sistematização diz respeito à identificação pela professora do que seria avaliado. Tal identificação é muito importante, já que a docente faria a mediação da leitura dramatizada para o aluno e também o ajudaria a compreender o enredo, a fim de que ele pudesse escrever o texto que ouviu.

Nesse sentido, foi selecionado, pela equipe da SEE-SP que elaborou a prova, um gênero textual: o conto. Para isso, houve a escolha de um trecho do conto "A troca e a tarefa", presente na obra Tchau, de Lygia Bojunga. A seleção considerou a brevidade característica dos contos, a temática do ciúme, recorrente em crianças e adolescentes que têm de repartir com os irmãos o amor dos familiares 
e a aparente clareza dos elementos da narrativa dispostos no texto (São Paulo, 2015, p. 4-5):

\section{O Ciúme e eu}

Eu tinha 9 anos quando a gente se encontrou: o Ciúme e eu. Era verão. Eu dormia no mesmo quarto que a minha irmã. A janela estava aberta. De repente, sem nem saber direito se eu estava acordada ou dormindo, eu senti direitinho que ele estava ali: entre a cama da irmã e a minha. A noite não tinha lua nem tinha estrela; e quando eu fui estender o braço para acender a luz ele não quis:

"Me deixa assim no escuro."

Que medo que me deu. Senti ele chegando cada vez mais perto. Fui me encolhendo.

"Pega a minha irmã", eu falei. "Ali, ó, na outra cama. Eu sou pequena e ela já fez 14 anos, pega ela! Ela é bonita e eu sou feia; o meu pai, a minha mãe, a minha tia, todo mundo prefere ela: por que você não prefere também?"

Mas o Ciúme não queria saber da minha irmã, e eu já estava tão espremida no canto (a minha cama era contra a parede) que eu não tinha mais para onde fugir, então eu pedia e pedia de novo:

"Ela é a primeira da turma e eu tenho horror de estudar, olha, ela está logo aí; ela é tão inteligente para conversar! Ela diz poesia, ela sabe dançar, o meu pai está ensinando inglês e francês para ela e diz que pra mim não vale a pena porque eu não presto atenção, então você pensa que eu não vejo o jeito que o meu pai olha pra ela quando todo mundo diz que encanto de moça que é a sua filha mais velha? Pega, pega, PEGA ela!"

"Não. Eu quero é você."

E o Ciúme disse aquilo com uma voz tão calma que eu fui me acalmando. E o medo meio que foi passando.

"Bom", eu acabei suspirando, "pelo menos tem alguém que gosta mais de mim do que dela".

[...]

BOJUNGA, Lygia. A troca e a tarefa. In: Tchau. Il. Regina Yolanda (miolo); Roger Mello (capa). 15. ed. Rio de Janeiro: Agir, 2000. p. 51.

O trecho selecionado para a Avaliação da Aprendizagem em Processo mostra uma narradora personagem que tem 9 anos e se sente preterida em relação à irmã mais velha, por quem alimenta um misto de admiração e ciúmes, já que, de acordo com o foco narrativo, a irmã mais velha teria as atenções da família por apresentar qualidades: é mais velha, bonita, estudiosa, inteligente, interessada pelos estudos, diz poesia, sabe dançar... Em meio a esse contexto de se sentir em segundo plano, a narradora vive o medo, na noite escura, do Ciúme: uma personificação que estaria ao lado da cama da garota, causando-lhe incômodo. No entanto, após expor oralmente ao visitante pavoroso o quanto ele também deveria preferir a irmã, mesmo que fosse para assustar a garota mais velha, a narradora, gradativamente, vai deixando a sensação de medo e rejeição, refletindo que, de alguma forma, a insistência do Ciúme em pegá-la e de rejeitar a irmã mais velha era, na verdade, uma forma de amor, de preferência por ela. Dessa forma, a menina de 9 anos acaba perdendo o medo.
A seguir, a tabela de identificação dos elementos da narrativa, a qual explicitou à docente a construção do texto, desde a apresentação da situação, passando pelo elemento complicador, até chegar à resolução.

Tabela 1. Os elementos da narrativa no conto

\begin{tabular}{|c|c|}
\hline $\begin{array}{l}\text { Elementos da } \\
\text { narrativa }\end{array}$ & Texto \\
\hline Personagens & $\begin{array}{l}\text { Eu tinha } 9 \text { anos quando a gente se encontrou: } \\
\text { o Ciúme e eu. }[\ldots]\end{array}$ \\
\hline Espaço (lugar) & $\begin{array}{l}{[\ldots] \text { eu dormia no mesmo quarto que a minha }} \\
\text { irmã. A janela estava aberta. }\end{array}$ \\
\hline Tempo & Era verão. \\
\hline Foco narrativo & $\begin{array}{l}\text { Narrador-personagem: Eu, minha irmã, eu } \\
\text { dormia (verbos e pronomes em primeira } \\
\text { pessoa) }\end{array}$ \\
\hline $\begin{array}{l}\text { Enredo } \\
\text { Início }\end{array}$ & $\begin{array}{l}\text { Eu tinha } 9 \text { anos quando a gente se encontrou: } \\
\text { o Ciúme e eu. }\end{array}$ \\
\hline $\begin{array}{l}\text { Elemento } \\
\text { complicador/ } \\
\text { conflito }\end{array}$ & $\begin{array}{l}\text { De repente, sem nem saber direito se eu estava } \\
\text { acordada ou dormindo, eu senti direitinho que } \\
\text { ele estava ali: entre a cama da irmã e a minha. } \\
\text { "Ela é a primeira da turma e eu tenho horror } \\
\text { de estudar, olha, ela tá logo aí; ela é tão inte- } \\
\text { ligente pra conversar! }\end{array}$ \\
\hline Clímax & $\begin{array}{l}\text { Ela diz poesia, ela sabe dançar, o meu pai está } \\
\text { ensinando inglês e francês pra ela e diz que } \\
\text { pra mim não vale a pena porque eu não presto } \\
\text { atenção, então você pensa que eu não vejo o } \\
\text { jeito que o meu pai olha pra ela quando todo } \\
\text { mundo diz que encanto de moça que é a sua } \\
\text { filha mais velha? Pega, pega, PEGA ela!" }\end{array}$ \\
\hline Desfecho & $\begin{array}{l}\text { E o Ciúme disse aquilo com uma voz tão calma } \\
\text { que eu fui me acalmando. E o medo meio que } \\
\text { foi passando. "Bom", eu acabei suspirando, } \\
\text { "pelo menos tem alguém que" }\end{array}$ \\
\hline
\end{tabular}

Fonte: Avaliação da Aprendizagem em Processo. 8.ed. Comentários e Recomendações Pedagógicas. São Paulo, 2015. p.8.

O texto "O Ciúme e eu" (título atribuído ao trecho do texto de Bojunga pelos elaboradores da prova), estava disponível apenas no material do professor (Recomendações Pedagógicas), para que a docente fizesse a leitura em voz alta. Os alunos deveriam saber que o texto seria lido pela professora em voz alta, pelo menos duas vezes, a fim de que todos pudessem ter a oportunidade de entender a história. No caso da turma envolvida, a leitura foi realizada três vezes, até que os estudantes se manifestaram satisfeitos e supostamente seguros com o enredo apresentado.

Primeiro, eles ouviram a história, depois retomaram oralmente as principais ações do texto, explicando com suas próprias palavras tudo o que tinha acontecido dentro da sequência exposta no conto. 
Em seguida, a professora explicou a eles que era importante escrever a história em uma folha de rascunho e, por último, após revisão, escrevê-la na folha oficial da produção de texto.

Durante a escrita. Quando iniciaram a escrita, os estudantes demonstraram muitas dúvidas quanto aos procedimentos para registrar o texto lido pela professora. Assim, iniciaram um momento de perguntas, pois queriam ter certeza de que estavam atendendo à solicitação adequadamente. Na Tabela 2, abaixo, estão algumas das questões feitas pelos estudantes e também aparecem as respostas oferecidas a eles.

Depois dos questionamentos, eles iniciaram a escrita do texto. Durante várias vezes, pediram a presença da professora na carteira deles, porque queriam confirmar se estavam acertando. Diante disso, a professora respondeu: "Façam o melhor que vocês puderem, mas fiquem tranquilos, porque o que vocês não souberem eu ensinarei depois, nas outras aulas, certo?".

Enquanto eles escreviam, a professora caminhava pela sala e observava a reação dos alunos: alguns pensativos, outros anotando no canto da folha as principais ações do texto, e alguns que nem sequer tinham começado a escrever. "Você quer que eu leia de novo a história?" (a professora perguntou para dois alunos que não estavam fazendo a atividade). Um deles disse que sim, portanto a leitura foi feita novamente para eles (em tom baixo de voz). Após essa nova leitura, ambos começaram a esboçar as primeiras palavras.
Considerando as reações dos alunos no momento da escrita, foi possível perceber o quanto vários deles se sentiam inseguros para realizar a atividade, e muitos nem sequer tinham noção de como utilizar a folha de papel almaço com pauta, a qual foi oferecida pela docente, para que servisse como rascunho. Diante disso, parecia que a maior parte dos estudantes não estava familiarizada com ações de escrita, como se produzir texto não fosse algo rotineiro.

Evidenciou-se a necessidade de desenvolver com a turma, em aulas futuras, um projeto de produção de texto, para que a escrita passasse a ser menos distante dos alunos. Nesse sentido, a docente percebeu a possibilidade de utilização da sequência didática dos pesquisadores genebrinos Dolz, Noverraz e Schneuwly (2004), já que ela tem a finalidade de ajudar o aluno a dominar melhor um gênero de texto, permitindolhe, assim, escrever, ler ou falar de uma maneira mais adequada numa dada situação comunicativa. Ela decompõe as atividades comunicativas complexas, que os estudantes ainda não são capazes de produzir sozinhos, para que possam estudar, um a um, os componentes que se mostrarem como obstáculos à aprendizagem e à realização do gênero discursivo. Funciona como instrumento de orientação ao trabalho docente, sistematizando o ensino.

Dolz, Noverraz e Schneuwly (2004, p. 98) explicam que a sequência didática é composta pelas seguintes etapas: apresentação da situação; produção inicial; módulos; produção final.

Tabela 2. Questionamentos dos alunos no ato da escrita

\section{Perguntas dos alunos}

Aluno L. S. - "Eu tenho de escrever o texto igualzinho ao que a senhora leu? Não posso esquecer nenhuma palavrinha?"

\begin{abstract}
Aluno R.S. - "Eu posso dar outro final ao texto, fazendo o Ciúme devorar a menina?"
\end{abstract}

\begin{abstract}
Aluno I.P.S. - "Eu escrevo a história como se eu fosse uma menina?" (Pergunta feita por um garoto)
\end{abstract}

\section{Respostas da professora}

"Você pode substituir uma palavra por outra de sentido semelhante, mas é importante que mantenha a mesma história que eu li aqui na classe."

"Olha que criativo! Vamos combinar assim: hoje você escreve a história do jeito que a professora leu, mas, na próxima produção de texto que faremos na classe, você cria a sua história, do jeito que achar mais legal, tudo bem?"

"Sim, você agora é um escritor, portanto imagina que é a garota de 9 anos que está com ciúmes da irmã, que está no quarto, etc. e escreve como se fosse ela."

"Você pode começar o texto desse jeito. Lembre-se de escrever a história completa, contando todos os detalhes."

"O ciúme e eu.".

"Se a personagem fala, você usa travessão, sim!"
Aluno M.C.S. - "Prô, quando a menina fala, naquela hora que ela manda o Ciúme pegar a irmã, eu tenho de usar aquele tracinho assim (a aluna faz um travessão na folha de papel) antes de começar a frase?" 
A apresentação da situação é a etapa de expor "aos alunos um projeto de comunicação que será realizado verdadeiramente na produção final" (DOLZ, NOVERRAZ e SCHNEUWLY, 2004, p. 99). É necessário definir o gênero discursivo a ser trabalhado, o destinatário, a forma que a produção assumirá (vídeo, impresso etc), quem participará do projeto; depois é necessário que os alunos saibam com quais conteúdos vão trabalhar e a importância desses conteúdos no texto em produção.

Na produção inicial, os alunos colocam em evidência, para si mesmos e para o professor, o que sabem sobre o gênero discursivo selecionado para estudo. Nesse momento, eles escrevem a primeira versão do texto.

Já na etapa módulos, o professor trabalha, separadamente, com os problemas que apareceram na produção inicial, ou seja, decompõe o gênero discursivo para abordar problemas de níveis diferentes, tais como a representação da situação comunicativa (a fim de focalizar o destinatário, ter clareza da finalidade da produção textual, saber seu papel como interlocutor e a função que o gênero discursivo selecionado exerce socialmente); a elaboração dos conteúdos (buscar, elaborar ou criar conteúdo de acordo com a especificidade de cada gênero); o planejamento do texto (manter certa padronização da estrutura composicional do gênero discursivo em foco); a realização do texto (escolher o vocabulário adequado, usar bem os verbos, trabalhar com os argumentos etc).

A última etapa é a produção final, a qual oportuniza ao aluno colocar em prática o que aprendeu ao longo dos módulos, ter consciência de seu próprio processo de aprendizagem e trabalhar como regulador de seu próprio comportamento na revisão e reescrita do texto que circulará socialmente.

Identificada a suposta necessidade de intervenção futura, o professor realiza a leitura dos textos escritos pelos alunos, a fim de constatar se a sequência didática pode ser aplicada nas aulas.

Depois da escrita. Para proceder a correção dos textos, o material do professor (Recomendações Pedagógicas) apresenta critérios a fim de ajudar na identificação das capacidades de escrita desenvolvidas ou não pelos estudantes. Tais critérios se sustentam em três eixos: 1. Tema; 2. Adequação às características do gênero; 3. Uso das convenções da escrita.

O eixo 1 diz respeito à escrita do texto que foi lido, ou seja, trata de verificar se o estudante escreveu o conto que trata a respeito de uma menina de 9 anos com ciúmes da irmã, mostrando que a garota estava no quarto em uma noite escura, quando o Ciúme apareceu e ela "conversou" com ele, pedindo a ele para que agarrasse a irmã mais velha.
Já o eixo 2 trata da utilização das características do gênero conto pelo estudante, evidenciando se este utilizou em seu texto os elementos da narrativa: tempo, espaço, personagens, enredo, foco narrativo em 1 a pessoa.

O último eixo diz respeito ao domínio das convenções da língua escrita, como paragrafação, ortografia, uso das letras maiúsculas e minúsculas etc.

A seguir, apresenta-se a grade de correção dos textos, conforme disposta no material oferecido pela SEE-SP.

Tabela 3. Modelo de grade de correção das produções dos alunos

\begin{tabular}{|c|c|c|}
\hline Critérios & Descritores & Pontuação \\
\hline $\begin{array}{l}\text { 1. Adequação } \\
\text { ao tema }(2,0)\end{array}$ & O texto reconta o que foi lido? & \\
\hline \multirow{8}{*}{$\begin{array}{l}\text { 2. Adequação às } \\
\text { características } \\
\text { do gênero }(4,0)\end{array}$} & $\begin{array}{l}\text { O tempo e o espaço estão } \\
\text { determinados? }\end{array}$ & \\
\hline & As personagens estão presentes? & \\
\hline & $\begin{array}{l}\text { Há introdução do elemento } \\
\text { complicador/conflito? }\end{array}$ & \\
\hline & $\begin{array}{l}\text { O texto garante a presença da } \\
\text { maioria dos acontecimentos } \\
\text { narrados? }\end{array}$ & \\
\hline & $\begin{array}{l}\text { Há condução ordenada no } \\
\text { desenvolvimento das ações? }\end{array}$ & \\
\hline & $\begin{array}{l}\text { Há relação de causa e } \\
\text { consequência entre os fatos } \\
\text { narrados? }\end{array}$ & \\
\hline & A narrativa está em $1^{\mathfrak{a}}$ pessoa? & \\
\hline & O conflito/desfecho é resolvido? & \\
\hline \multirow{8}{*}{$\begin{array}{l}\text { 3. Uso das } \\
\text { convenções da } \\
\text { escrita }(4,0)\end{array}$} & $\begin{array}{l}\text { As palavras estão segmentadas } \\
\text { corretamente? }\end{array}$ & \\
\hline & $\begin{array}{l}\text { As palavras obedecem às regras } \\
\text { ortográficas? }\end{array}$ & \\
\hline & $\begin{array}{l}\text { O texto apresenta } \\
\text { adequadamente letras } \\
\text { maiúsculas e minúsculas? }\end{array}$ & \\
\hline & A pontuação está adequada? & \\
\hline & $\begin{array}{l}\text { O discurso direto e/ou indireto é } \\
\text { utilizado adequadamente? }\end{array}$ & \\
\hline & $\begin{array}{l}\text { O texto apresenta uso adequado } \\
\text { de concordância nominal e } \\
\text { verbal? }\end{array}$ & \\
\hline & A paragrafação está adequada? & \\
\hline & $\begin{array}{l}\text { Sinônimos são utilizados para } \\
\text { evitar repetição de determinadas } \\
\text { palavras? }\end{array}$ & \\
\hline
\end{tabular}

Fonte: Avaliação da Aprendizagem em Processo. 8. ed. Comentários e Recomendações Pedagógicas (São Paulo, 2015, p. 7)

A professora leu todos os textos escritos pelos alunos e realizou o preenchimento da grade de correção. A seguir estão alguns exemplares de textos escritos pelos alunos. 
Produção do aluno R. C. A. - 11 anos:

\section{O ciueme e éu}

Eu tia nove codó a geite coeseu O siume e éu era vera eubormia no memo qua to coua mia irma a janela tava aberta eu nei sadia eu estava ei pé seu estava está o siume a para reseu eu leveius suto eu vaei pega a mia irma ela está beidoseu lado não eu quero você ela é amelo a luna dasala ela éute lijeite melor doqueéu meu pai inglês e faleis vai para ela não quero você ciueme faluta caumo quemeu coração alavio.

\section{Produção do aluno L. S. - 12 anos:}

O ciúme e eu

Era um certo dia eu tinha 9 anos estava sem estrela e sem lua estava escuro a janela estava aberta e o ciúme estava do meu lado ele chegava, mas perto e eu encolhia eu falei pega minha irmão ela e mais inteligente ela e a melhor da turma ela melhor do que eu meu pai ensina inglês e francês para ela ela e mas inteligente não quero você bom pelo menos alguém gosta mais de mim do que ela.

\section{Produção do aluno M. C. S. - 12 anos:}

\section{O ciúme e eu}

Eu tinha 09 anos quando eu conheci o ciúme e eu. Uma noite de verão no quarto junto com minha irmã, a janela estava aberta não tinha lua nem estrela nem sabia se eu estava acordado ou dormindo quando senti eu sabia quem estava lá era o ciúme eu foi estender o braço para acender a luz. Disse o ciúme

- Não acende a luz.

Pega à minha irmã ela é bonita é eu não, ela e inteligente e é a 1 a da turma meu pai está ensinando para ela inglês e francês para ela vai pega logo.

Não eu quero você. Disse o ciúme

Pelo menos alguém gosta de mim do que ela.

\section{Produção do aluno I. P. A. - 11 anos:}

\section{O ciúme e eu}

Eu tinha 9 anos, quando a gente se encontrou, o ciúme e eu. Era verão, eu dormia no mesmo quarto da minha irmã.

A janela estava aberta, o céu estava sem lua e estrelas.

Eu não sabia se estava acordada ou não, mas eu sento direitinho ele entre a minha cama e a da minha irmã.

Eu ia acender a luz, mas ele falou:

- Não! Me deixa no escuro assim.

- Aí que medo me deu, então eu fui me encolhendo e falei:

- Pega minha irmã ela e bonita esperta, fala poesias.

Ele não respondeu, eu me encolhi mais ainda e falei:

- Pega ela, ela é a primeira da turma, já eu odeio estudar, meu pai está ensinando ingles e fraces para ela, pega ele, pega ela! - Não! Eu quero você!

Dos 26 alunos que realizaram a escrita $(100 \%$ da turma), utilizando os critérios de correção, foi possível organizar 4 grupos a partir do domínio da língua escrita:
Grupo 1 ("aluno I. P. A" +4 alunos $=20 \%$ da turma). Alunos que elaboram textos com sentido completo e que escrevem a maior parte das ações narrativas, com uso básico das convenções da língua escrita, embora ainda cometam alguns equívocos na estruturação textual, problemas simples na organização dos parágrafos, ortografia comprometida em algumas palavras, casos de segmentação indevida em alguns vocábulos, discurso direto nem sempre marcado adequadamente, baixo uso dos sinais de pontuação, alguns problemas de mistura de foco narrativo, baixo uso de palavras para substituir e evitar repetições e, às vezes, uso indevido das linhas na folha de papel.

Grupo 2 ("aluno M. C. S." + cinco alunos $=23 \%$ da turma). Alunos que elaboram textos com sentido, mas não dominam o uso das convenções da língua escrita, no que diz respeito à estruturação textual: organização/ separação dos parágrafos, uso do discurso direto, além de apresentarem desvios na grafia convencional dos vocábulos, casos de segmentação indevida, uso indevido de letra minúscula, pontuação faltante, troca de foco narrativo ao longo do texto e, às vezes, uso indevido das linhas na folha de papel.

Grupo 3 ("aluno L. S." +10 alunos $=42 \%$ da turma). Alunos que elaboram textos com problemas de sentido, pois não conseguem manter um foco narrativo ou a sequência das ações, gerando, em certos momentos, amontoados de ideias desconexas ou brevidade de ações, que não são capazes de sustentar os elementos da narrativa. A maioria dos estudantes deste grupo escreve o texto em um único parágrafo, sem qualquer sinal de pontuação; os alunos que tentam separar as ideias em parágrafos não dominam a organização textual, usando indevidamente o discurso direto ou outro elemento de pontuação. Aparecem nos textos desvios na grafia convencional dos vocábulos, problemas com segmentação, registro da variante informal, uso indevido de letra minúscula, e, em alguns casos, desconhecimento quanto ao uso das margens da folha de papel. São alunos que demonstram pouca intimidade com a língua escrita, no que se refere à elaboração de textos em prosa, já que grafam sequências de palavras, sem as marcas comuns da produção textual escrita.

Grupo 4 ("aluno R. C. A." + três alunos $=15 \%$ da turma). Alunos que não elaboram textos, mas sim amontoados de frases, sempre curtas, às vezes, incompletas e desarticuladas entre si. Não há, na escrita, aparente sequência das ações, e faltam quase todos os elementos da narrativa. Todos os estudantes deste grupo escrevem o texto em um único e breve parágrafo, sem qualquer sinal de pontuação, nem mesmo respeito aos espaços de margem ou à troca adequada das linhas do papel. Há diversos desvios na grafia convencional dos 
vocábulos e, em alguns casos, presença de trechos ilegíveis e incoerentes. Tais alunos não demonstram segurança quanto às escolhas linguísticas para a escrita, trocam letras dos vocábulos (evidenciando problemas com fonemas), segmentam demais em alguns casos e não segmentam em outros, mantendo duas palavras juntas. Falta organização do texto na página, falta também uso das letras maiúsculas e minúsculas, além disso, há casos de uso de letra bastão, com traço bastante rudimentar. Alguns desses alunos deixaram evidente a falta de firmeza para registro da língua escrita, demonstrando também insegurança para ler a própria produção. São alunos que não demonstram intimidade com a língua escrita, no que se refere à escrita de vocábulos simples, tampouco elaboração de textos.

Após a sistematização dos dados de correção houve uma devolutiva sobre a escrita do texto "O Ciúme e eu”, e cada aluno recebeu uma grade de correção, na qual estavam evidenciados os pontos fortes e frágeis de cada texto. A professora conversou com eles sobre o desempenho da turma, que solicitou um estudo para escrever melhor, mostrando que deseja produzir textos e até publicar um livro de histórias.

Considerando o pedido dos alunos e os resultados obtidos na correção dos textos produzidos por eles, mostrou-se necessária uma intervenção intensiva, com o desenvolvimento de um trabalho sistematizado com a escrita. Portanto, confirmou-se a relevância da sequência didática, a fim de que os estudantes tenham a oportunidade de estudar detalhadamente o processo de escrita, tendo como objeto o gênero textual conto. Os módulos da sequência didática poderão oportunizar aos estudantes a reflexão sobre a língua escrita no intuito de diminuir a dificuldade destes.

Diante disso, foi construída uma proposta de intervenção didática.

\section{Proposta de UMA SEquÊnCIA DIDÁTICA}

A seguir, apresenta-se uma proposta de sequência didática (SD) para produção do gênero textual conto, com nove atividades, organizadas, de acordo com a teoria da SD, apontada neste artigo: apresentação da situação (atividades 1, 2 e 3), produção inicial (atividade 4), módulos (atividades 5, 6 e 7) e produção final (atividades 8 e 9 ).

O objetivo dessa proposta é oferecer uma "modelagem", ou seja, servir como parâmetro para que os docentes possam pensar em suas próprias SDs, a partir das necessidades formativas de cada turma de estudantes da escolaridade básica. Com base nos dizeres de Colomer e Camps (2002, p. 84), o estágio de modelagem proporciona a exposição de processos implicados no fazer, servindo de apoio ao aprendente.

Esse trabalho com a SD permite pensar em atividades de caráter modular: por etapas e com tarefas específicas, sempre dando autonomia ao docente que avalia os saberes de seus alunos para propor reflexões e momentos de aprendizagem segundo as necessidades. Para Marcuschi,

a modularidade permite um trabalho diferenciado entre os alunos e permite que se tenha atenção para problemas específicos de cada qual na medida em que se acompanham as produções individuais e se fazem avaliações específicas da produção corrente. A produção do aluno é valorizada (MARCUSCHI, 2009, p. 217).

Além disso, a reflexão em grupo sobre aspectos da produção textual amplia as oportunidades de aprendizagem dos estudantes, porque cria espaços para socialização de conhecimentos e coloca o grupo numa grande rede de compartilhamento de saberes, com foco em um aspecto do texto por vez.

as situações didáticas de produção textual permitem dispor juntos conhecimentos diferentes proporcionados por distintos membros do grupo e, nessa medida, tornam possível constituir como conteúdos de reflexão atividades do escritor e conteúdos linguísticos que estão simplesmente em ação em outras situações. É assim que - para dar apenas um exemplo - um comportamento, como evitar repetições desnecessárias, pode levar a refletir sobre a conveniência de substituir por outros elementos lexicais ou substituir por pronomes ou suprimir o elemento repetido (LERNER, 2002, p. 65).

Apresentam-se, a seguir, as atividades de uma SD (dispostas em caixas de texto), bem como as considerações sobre a relevância das atividades para o desenvolvimento da aprendizagem dos alunos.

ATIVIDADE 1 - Entre leituras e escritas: interação inicial. Esta atividade é para interagir com os alunos, mostrando para eles a importância da escrita na sociedade, bem como a singularidade do gênero discursivo conto. De acordo com os criadores do procedimento sequência didática, Dolz, Noverraz e Schneuwly (2004, p. 99), a apresentação da situação é a "etapa que envolve a proposta de um projeto verdadeiro de produção de texto, que apresenta o problema de comunicação e prepara os conteúdos que integrarão o texto". Assim, a Atividade 1 pode realizar um diálogo com o estudante, intenciona convidar o aluno a participar do projeto de desenvolvimento da $\mathrm{SD}$, porque visa ao envolvimento do aluno com a própria aprendizagem, vinculando-o e ao mundo real e explicitando que não se trata de apenas 
uma atividade escolar, mas de uma aprendizagem necessária à vida.

Sugestão para o aquecimento:
Olá! Você que já está no $6^{\circ}$ ano, já leu e escreveu muito na sua
vida escolar, não é mesmo?
Além das atividades escolares, que outros textos você já leu em
sua vida? Em que situações? Por quê?
Quanto à escrita, ademais dos trabalhos escolares, das pesquisas,
das provas etc., quais outros textos você já escreveu? Você faz
postagens em alguma rede social, na internet? Envia mensagens
pelo celular? Já escreveu alguma carta ou e-mail de amor? Já
preencheu algum documento?
Em sua opinião, saber ler e escrever é importante? Por quê?
Pensando nisso, que tal estudarmos um pouco mais sobre a
construção de textos narrativos, como o conto?

ATIVIDAde 2 - Reconhecendo o conto. Para esta atividade, recomenda-se que o professor selecione três textos: uma notícia; um anúncio publicitário; um conto. Que ofereça esses textos aos alunos, a fim de que façam o estudo e percebam a função social de cada um, a composição/estrutura de cada gênero, a maneira como a linguagem é empregada etc. Seguem sugestões de perguntas. É importante orientar os alunos na percepção de que o conto é composto por elementos da narrativa. A atividade se justifica pela capacidade de mobilizar os saberes dos alunos sobre os diferentes textos e por fazê-los perceber o quanto os recursos linguísticos e multissemióticos se organizam para a construção discursiva. Propõe ainda um diagnóstico do que os estudantes pensam e sabem sobre o gênero discursivo em estudo. Para isso, existem três textos a serem lidos e classificados quanto ao gênero e à finalidade. Tal atividade consiste em uma comparação entre diferentes gêneros discursivos, evidenciando as peculiaridades quanto ao contexto de produção e temas comuns a cada gênero.

\section{Sugestão:}

Leia atentamente os textos 1, 2 e 3 . Em seguida, responda às perguntas que estão no quadro abaixo:

\begin{tabular}{|l|l|l|l|}
\hline Perguntas & Texto 1 & Texto 2 & Texto 3 \\
\hline $\begin{array}{l}\text { A que gênero textual pertence cada } \\
\text { texto? }\end{array}$ & & & \\
\hline Quem produziu o texto? & & & \\
\hline Para quem se destina? & & & \\
\hline Onde foi publicado? & & & \\
\hline Qual o tema tratado no texto? & & & \\
\hline Qual parece ser o objetivo do texto? & & & \\
\hline $\begin{array}{l}\text { Existe uso dos elementos da } \\
\text { narrativa no texto? Justifique. }\end{array}$ & & & \\
\hline
\end{tabular}

ATIVIDAde 3 -Aprofundando no conteúdo do texto. Esta atividade é para o estudo pormenorizado do conto, usado na atividade 2. É possível acrescentar um ou dois outros contos, ampliando também as perguntas sugeridas na atividade. É solicitado que os alunos voltem ao conto lido na atividade anterior e que percebam a diferença entre a apresentação de fatos (da notícia) e a construção de um enredo, por exemplo. Além disso, a atividade incentiva os alunos a encontrarem os elementos da narrativa.

\section{Sugestão:}

Volte ao conto lido na atividade 2 e responda:

a) Qual a principal diferença entre esse texto e os outros textos lidos na atividade 2?

b) Qual o assunto principal tratado no conto?

c) Como você interpreta o título do texto?

d) Como aparecem os elementos da narrativa no conto?

e) Como estão organizados os parágrafos do conto? E dos demais textos?

f) Como é a linguagem em cada um dos textos?

ATividade 4 - Proposta de produção de um conto. Esta atividade é para a primeira escrita de autoria de um conto. Definir com a turma uma temática, sobre a qual cada aluno, individualmente, escreverá. Ainda durante essa conversa, a atividade requer que o grupo defina o local de publicação do texto, os leitores pretendidos e os locais de circulação do texto. A produção inicial consiste em uma avaliação formativa, pois permite ao professor conhecer o que pensam seus alunos sobre determinado gênero, além de diagnosticar as capacidades de linguagem que eles têm. Ao definir um motivo social que justifique a produção do texto, a atividade assume um vínculo com a realidade e não um mero fim escolar. Além disso, a garantia da circulação real do texto também dá sentido à atividade escolar, motiva os alunos e oferece condições para que a prática social da leitura e da escrita aconteça na aula.

\section{Sugestão:}

Agora chegou o momento de produzir um conto! Você e sua turma vão escrever a primeira versão do texto, a fim de que seu professor avalie o que vocês sabem e possa ajudá-los na melhoria da qualidade de escrita.

Para a primeira produção, é necessário definir os itens apontados no quadro abaixo:

\begin{tabular}{|l|l|}
\hline Gênero textual a ser produzido & Conto \\
\hline Temática & \\
\hline Onde o texto final será publicado & \\
\hline Público-alvo do texto & \\
\hline Locais de circulação do texto & \\
\hline
\end{tabular}


ATIVIDADE 5 - A representação da situação comunicativa de um conto. Depois que a turma já produziu a primeira versão do texto, é importante fazer uma correção e socializar os resultados com os estudantes, dando a eles condições de compreenderem o que dominam ou não no processo de escrita do conto. Em seguida, convém preparar atividades para tratar separadamente cada uma das dificuldades dos alunos. Esta é a terceira etapa da SD - módulos. Para Dolz, Noverraz e Schneuwly (2004, p. 103), "nos módulos, trata-se de trabalhar os problemas que apareceram na primeira produção e de dar aos alunos os instrumentos necessários para superá-los". Caso as atividades mencionadas neste artigo não contemplem todas as necessidades de seus alunos, outras atividades complementares podem ser elaboradas. A atividade 5 objetiva levar os alunos a compreender que todo texto é construído em um contexto. Em primeiro lugar, é interessante apresentar um conto para a leitura, a partir do qual os estudantes podem identificar os elementos do contexto: autor do texto, papel social do autor do texto; interlocutores, representação social dos interlocutores; finalidade/objetivo do texto; circulação do texto. Esta atividade visa a retomar a influência do contexto na produção dos discursos.

\section{Sugestão:}

Leia outro conto selecionado por seu professor e, em seguida, responda:

a) Onde o texto foi publicado?

b) O texto poderia ser publicado em outro lugar? Qual?

c) Quem o escreveu?

d) Que tipo de informações sobre o autor estão disponíveis?

e) Como essas informações se relacionam com o texto?

f) A quem se destina o texto?

Retome todos os contos lidos até o momento e preencha, com a ajuda de seu professor, o quadro abaixo:

\begin{tabular}{|l|l|}
\hline \multicolumn{2}{|c|}{ Contexto de produção de um conto } \\
\hline a) Autor do texto & \\
\hline $\begin{array}{l}\text { Papel social } \\
\text { b) Interlocutores }\end{array}$ & \\
\hline $\begin{array}{l}\text { Representação social } \\
\text { c) Finalidade do texto }\end{array}$ & \\
d) Circulação do texto & \\
\hline
\end{tabular}

ATIVIDAde 6 - A elaboração dos conteúdos, utilização da linguagem, planejamento e realização de um conto. Esta atividade é composta por questões que exploram a composição narrativa do texto.

\section{Sugestão:}

Releia os contos indicados por seu professor para responder às questões seguintes: a) Qual o assunto geral de cada texto? Qual o valor social desse(s) assunto(s)?

b) Quais os problemas vividos pelos personagens?

c) Em quantos parágrafos está estruturado cada texto? Qual a ideia central de cada parágrafo?

d) Como é a situação inicial em cada texto?

e) Quais as personagens principais? O que elas têm de especial/ diferente das outras personagens?

f) O narrador participa das histórias?

g) Que linguagem é usada em cada texto: formal/informal? Comprove sua resposta.

h) Você considera que os autores planejaram a elaboração dos textos, ou seja, eles pensaram em como iriam construir cada parágrafo, como tratariam cada ideia? Em sua opinião, quais etapas foram necessárias para que cada autor pudesse planejar o texto?

i) Que tempos verbais prevalecem em cada texto? Qual a relação entre o uso de tais verbos e a construção do sentido do texto?

j) Há uso de pronomes ou demais elementos organizadores do texto? Quais? Como eles são usados? Como interferem na construção do sentido do artigo? Sem eles, o texto seria igual?

ATIVIDade 7 - Analisando em conjunto as primeiras produções da turma. São selecionados dois textos produzidos por alunos da turma durante a primeira produção para realizar uma atividade de reescrita coletiva de trechos de um dos textos, estudando com eles o que pode ser melhorado e por quê. Depois, é possível oferecer um trecho do outro texto selecionado para análise e pedir para que, em duplas, os alunos façam a reescrita do trecho, apontando o que foi alterado. O objetivo é colocar em prática a aprendizagem construída durante a atividade 6 , identificando os elementos que carecem de alteração nos textos da turma, relacionados à textualidade, à coerência e à coesão textual.

\section{Sugestão:}

Seu professor selecionou alguns dos textos produzidos pela turma na atividade 4 , a fim de que, coletivamente, seja estudado cada elemento que compõe a elaboração do conteúdo do artigo de opinião, envolvendo o planejamento e a escrita do texto.

A partir de agora, a classe participará da leitura de alguns exemplares, para ajudar a reconstruir os aspectos apontados pelo docente nas anotações que acompanham cada texto. Tudo será registrado em forma de sugestão, para que o autor do texto, depois, possa refletir sobre as ideias dadas e acatá-las ou não.

São considerações relativas à estruturação dos parágrafos, construção dos argumentos; uso de vozes no texto; uso da linguagem; efeito das modalizações; construção de lógica e da textualidade; uso de elementos coesivos.

Então, mãos à obra! 
Atividade 8 - Planejando a (re)escrita do texto individual. A atividade convida o aluno a planejar a produção do texto, retomando o projeto de comunicação definido no início da SD e propondo a alimentação dos conteúdos que farão parte da produção final. O professor pode ajudar seu aluno a elaborar o planejamento, com um roteiro.

\section{Sugestão:}

Enfim chegou a hora de cada aluno escrever (ou reescrever) seu conto. Para isso, é preciso planejar o que será escrito, realizar pesquisas para levantamento de conteúdos, escolher o vocabulário adequado.

Elabore, portanto, seu planejamento de texto e o compartilhe com um colega, para que este verifique se todos os aspectos do conto foram considerados. Assim você analisa o planejamento de seu amigo e ele analisa o seu. Reveja tudo o que você estudou sobre o conto e bom planejamento!

ATIVIDAde 9 - Produção final e divulgação do conto. A atividade pretende criar espaço para a (re) escrita do texto pelo aluno. Para orientar o estudante, há uma grade de avaliação do gênero discursivo, a qual permite verificar a adequação de cada item no texto reescrito, com base no que foi estudado durante a SD. O aluno usa a grade enquanto (re) escreve o texto. Para o professor, a grade pode ser usada também como critério de correção e estabelecimento de nota. A publicação do texto garantirá uma circulação social aos artigos de opinião e atribuirá sentido à produção de texto na escola.

\section{Sugestão:}

Escreva ou reescreva seu texto. Antes de publicá-lo, no local combinado pela turma durante a atividade 4 , utilize esta grade para avaliar sua produção. Seu professor também utilizará esta grade para, mais tarde, corrigir o seu texto.

\begin{tabular}{|l|l|l|}
\hline Critérios & $\begin{array}{c}\text { O que está } \\
\text { adequado? }\end{array}$ & $\begin{array}{c}\text { O que é preciso } \\
\text { mudar? }\end{array}$ \\
\hline Adequação do título & & \\
\hline Existe situação inicial? & & \\
\hline $\begin{array}{l}\text { Acontece um problema que } \\
\text { desequilibra a história? }\end{array}$ & & \\
\hline $\begin{array}{l}\text { O personagem realiza várias } \\
\text { ações para resolver o problema? }\end{array}$ & & \\
\hline O conflito é resolvido? & & \\
\hline $\begin{array}{l}\text { Existe uso de discurso direto } \\
\text { quando os personagens falam? }\end{array}$ & & \\
\hline $\begin{array}{l}\text { Os pronomes ou outras formas de } \\
\text { substituição de repetições estão } \\
\text { bem empregados? }\end{array}$ & & \\
\hline Existe uma conclusão adequada? & & \\
\hline $\begin{array}{l}\text { O texto está organizado em } \\
\text { parágrafos? }\end{array}$ & & \\
\hline $\begin{array}{l}\text { O texto está legível? Há respeito } \\
\text { pela ortografia, pela pontuação? }\end{array}$ & & \\
\hline
\end{tabular}

As atividades anteriormente apresentadas expressam, essencialmente, uma oportunidade de reflexão sobre a produção do gênero textual conto, no sentido de o professor criar oportunidades para os alunos aprenderem a escrever em situações reais de escrita: com o objetivo de fazer o texto circular socialmente, com público alvo e local de publicação bem definidos. Ofertar atividades reflexivas aos alunos é, segundo Guedes (2009, p. 92), acreditar no papel de mediação docente, descaracterizando preconceitos de que a escrita seja um dom para poucos, já que, na verdade, todos podem aprender a produzir textos na escola.

\section{CONSIDERAÇõES FINAIS}

Em linhas gerais, é possível afirmar que a turma de $6^{\circ}$ ano envolvida nessa Avaliação da Aprendizagem em Processo (Produção Textual) sabe compreender o tema solicitado na escrita, pois todos escreveram sobre o texto lido na aula. Além disso, quando expuseram oralmente as ações do texto, conseguiram recuperar adequadamente a sequência textual.

Por outro lado, quando escrevem cometem desvios referentes ao registro de todos os elementos da narrativa e ao domínio das convenções da língua escrita, comprometendo a construção dos elementos constitutivos do gênero conto.

Assim, no intuito de colaborar com o desempenho dos alunos, nasceu uma proposta de intervenção pedagógica, na qual prevalece a sequência didática como uma oportunidade de sistematizar o ensino. Portanto, ela tende a acrescentar muito na qualidade formativa dos alunos, pois é didaticamente organizada para fazer o estudante pensar em cada etapa de elaboração de um gênero discursivo, reconhecendo a situação comunicativa; a forma, o estilo e o conteúdo do texto em construção; estudando aspectos linguísticos e extralinguísticos que colaboram na construção textual.

Vale destacar que a figura do mediador é essencial no processo de aprendizagem, ou seja, o professor é quem, de fato, pode avaliar os saberes iniciais dos estudantes e propor a eles o desenvolvimento de atividades de produção textual que ajudem na ampliação e fortalecimento das capacidades linguísticas. É fato também que o sucesso da aprendizagem está subordinado a variáveis que podem influenciar o fazer docente. Desse modo, a SD aqui proposta tem o objetivo de criar espaços de socialização de pesquisas e diálogos com os educadores, e, por não ter caráter arbitrário, tampouco despreza a autonomia do professor na construção de intervenções didáticas. 


\section{REFERÊNCIAS}

COLOMER, Teresa; CAMPS, Anna. Ensinar a ler, ensinar a compreender. Porto Alegre: Artmed, 2002.

DOLZ, Joaquim; GAGNON, Roxane; DECÂNDIO, Fabrício. Produção escrita e dificuldades de aprendizagem. Trad. de Fabrício Decândio e Anna Rachel Machado. Campinas, SP: Mercado de Letras, 2010.

DOLZ, Joaquim; NOVERRAZ, Michele; SCHNEUWLY, Bernard. Sequências didáticas para o oral e a escrita: apresentação de um procedimento. In: DOLZ, J.; SCHNEUWLY, B. (Org.). Gêneros orais e escritos na escola. Trad. de Roxane Rojo e Glaís Sales Cordeiro. Campinas: Mercado de Letras, 2004. p. 21-39.

GUEDES, Paulo Coimbra. Da redação à produção textual: 0 ensino da escrita. São Paulo: Parábola, 2009.
LERNER, Delia. Ler e escrever na escola: o real, o possível e o necessário. Porto Alegre: Artmed, 2002.

MARCUSCHI. Luiz Antônio. Produção textual, análise de gêneros e compreensão. São Paulo: Parábola, 2009.

SÃO PAULO. Secretaria da Educação. Avaliação da aprendizagem em processo: comentários e recomendações Pedagógicas - 60 ano. 8. ed. São Paulo, 2015.

SOARES, Magda. A escolarização da literatura infantil e juvenil. A escolarização da leitura literária. Belo Horizonte: Autêntica, 2003.

SOARES, Magda. Letramento: um tema em três gêneros. Belo Horizonte: Autêntica, 2002.

Recebido em 16-04-2017.

Aprovado em 13-07-2017. 